\title{
Book Review: \\ Handbook of Research on Educational Communications and Technology
}

\author{
Rauf Yildiz \\ Canakkale Onsekiz Mart University, Turkey
}

\begin{abstract}
Introduction
This third edition of the Handbook of Research on Educational Communications and Technology is edited by J. Michael Spector (Florida State University), M. David Merrill (Utah State University), Jeroen J.G. van Merrienboer (Open University of the Netherlands), and Marcy P. Driscoll (Florida State University). It is published in 2008 by Lawrence Erlbaum Associates (ISBN-13: 978-0-8058-5849-5). The book is organized in six major parts: (1) Foundations; (2) Strategies; (3) Technologies; (4) Models; (5) Design and Development; (6) Research Methodologies. These parts reflect fundamental issues and applications involved in deploying information and communications technologies for educational purposes. Each part is led by one of the coeditors with assistance from a second coeditor and several external reviewers.
\end{abstract}

The Handbook is considered to primarily be useful for doctoral students initiating a research review for their dissertation studies, for faculty as an additional resource for teaching courses on related topics, and for researchers seeking a quick review on a specific topic. All chapters have extensive lists of useful references for researchers who are new to a particular area of study and for doctoral students conducting their background research. Professional educators and educational researchers can also benefit particularly from the chapters in Parts I and VI. These chapters, as well as many others in the Handbook, are likely to be useful for those responsible for leading graduate seminars in the areas of educational technology, instructional systems, or learning environment design and development.

Part I, led by Marcy P. Driscoll with assistance from J. Michael Spector, includes historical, theoretical, and methodological foundations and perspectives. Part II, led by M. David Merrill, focuses on strategies. Part III, led by J. Michael Spector, focuses on technologies. Part IV, led by Jeroen van Merrienboer, focuses on models. Part V, led by M. David Merrill, focuses on design and development. Part VI, led by Jeroen van Merrienboer, focuses on methodological issues. Let us now examine each part separately in more details.

\section{Part I: Foundations}

As indicated earlier, this part of the Handbook is led by Marcy P. Driscoll with assistance from J. Michael Spector. It focuses on various sets of assumptions that underlie research in educational communications and technology. Some of these assumptions are based on what has gone before. Others are based on developments in other disciplines. The goal in this part is to make these assumptions explicit, summarize key developments, and provide 
pointers to exemplary work that has implications for research in educational communications and technology. This part of the Handbook consists of seven chapters covering: (1) historical foundations, (2) theoretical foundations, (3) complexity theory, (4) experiential perspectives, (5) empirical perspectives, (6) contextualistic perspectives, and (7) philosophical perspectives.

\section{Chapter 1: Historical Foundations}

This chapter is written by Michael Molenda of Indiana University, USA. The chapter can be summarized as follows: Research and practice in educational technology are rooted in a primordial human drive to find ways of teaching in ways that are more efficient. Every civilization has developed formal methods of education more efficacious than the trial-and-error of everyday living. In the first decades of the 20th century, individuals and, later, groups of affiliated professionals made that quest a central focus, thus establishing educational technology as a field. Their first activities aimed at enriching the learning experience with visual and later audio-visual resources. As radio broadcasting grew in the 1930s and then television in the 1950s, these mass media were accepted as ways to reach even larger audiences, in and out of school, with educative audio-visual programs. In the 1960s, the wave of interest in teaching machines incorporating programmed instruction based on behaviorist psychology engulfed the field, engendering a shift in identity. The proper study of the field expanded from audio-visual technologies to all technologies, including psychological ones. By the 1980s, the center of gravity had shifted to the design of instructional systems, especially the adroit application of instructional methods, enlivened by fresh insights from cognitive and constructivist perspectives. As computers became ubiquitous in the 1990s, they became the delivery system of choice due to their interactive capabilities. With the rapid global spread of the World Wide Web after 1995, networked computers took on communication functions as well as storage and processing functions. The 21st century began with educational technology that increasingly focused on distance education, the latest paradigmatic framework for its ageless mission to help more people learn faster, better, and more affordably.

\section{Chapter 2: Theoretical Foundations}

This chapter is written by J. Michael Spector of Florida State University, USA. The chapter addresses the theoretical foundations for research in educational communications and technology. Four relevant areas are explored: (1) the psychology of learning, (2) communications theory, (3) human-computer interaction, and (4) instructional design and development. Past work in these four areas can be viewed as providing a theoretical foundation for further research and development in educational communications and technology.

\section{Chapter 3: Complexity Theory}

This chapter is written by Xiaopeng Ni and Robert Maribe Branch of University of Georgia, USA. The chapter can be summarized as follows: Complexity is a common phenomenon existing in biological organisms, geological formations, and social constructions. Educational researchers and educational practitioners routinely encounter complex situations as a function of study and practice. Managing complex situations has become a common necessity for educational technology researchers to make sense of complicated situations; however, complexity as a 
factor in educational technology research tends to be malaligned, oversimplified, or otherwise insufficiently addressed, thereby rendering the results of many research studies about educational technology lacking in generalizability. A conceptual, theoretical, and practical understanding of complexity offers a framework for research on educational technology that addresses the issues associated with nonlinear and complicated relationships. Complexity theory is predicated on a phenomenon possessing five attributes: (1) it contains independent complicated entities; (2) multiple entities are contained within; (3) the entities within the phenomenon perform interrelated functions; $(4)$ the phenomenon seeks a common goal; and (5) uncertainty is generated because of unpredictable interactions within itself and between itself and the environment. A summary of the main conceptual, theoretical, and practical aspects of complexity is presented as it relates to educational communications and technology.

\section{Chapter 4: Experiential Perspectives}

This chapter is written by Konrad Morgan of Northern Alberta Institute of Technology, Canada. The author claims that a review of modern perspectives on learning would not be complete without some mention of the increasing awareness that we now have of the importance of experiential learning and its relationship in developing not only domain skills within the learner but also an understanding of new applications for such domain skills. The author discusses experiential learning in a modern perspective and provides the reader with a deeper understanding of the concepts associated with these ideas and the likely future directions for applying experiential leaning within the context of technology-enhanced lifetime learning.

\section{Chapter 5: Empirical Perspectives on Memory and Motivation}

This chapter is written by Norbert M. Seel of Florida State University, USA. It focuses on empirical research on memory and motivation within the realm of educational communication and technology. A variety of research methods and methodologies are described, with emphasis on the accessibility of theoretical constructs such as memory and motivation and the validity and reliability of assessments. The abundance of issues surrounding memory and motivation are discussed within the realm of educational communication and technology. Several theoretical approaches to the architecture of cognition and models of human memory are described and discussed with regard to the question of how experiences with media and human memory interact. Accordingly, cognitive load theory and dualcode processing, as well as the theories of schemata and mental models, are reviewed critically and evaluated with regard to their advantages and drawbacks for learning with media. This chapter furthermore introduces relevant motivational research issues concerning technology-enhanced learning. After a description of several theoretical approaches concerning relevant motivational factors, the empirical research dealing with the question of how media and motivation interact are reviewed and evaluated.

\section{Chapter 6: Contextualistic Perspectives}

This chapter is written by Eric J. Fox of Western Michigan University, USA. The chapter provides an overview of Stephen Pepper's philosophical worldviews (1942) as a way of clarifying the 
philosophical assumptions of different perspectives. A detailed analysis of contextualism is provided, and the manner in which this worldview relates to both constructivist and behavioral theories in instructional design is explicated.

\section{Chapter 7: Philosophical Perspectives}

This chapter is written by Eric Kathy L. Schuh (University of lowa), and Sasha A. Barab (Indiana University), USA. In this chapter, the authors discuss that philosophical perspectives are worldviews that define the nature of the world, the individual's place in it, and the possible relationships to that world and its parts. Learning and instructional theories are developed with respect to a particular set of assumptions regarding what it means to know and learn. They point out that when situational variables require some decision on the part of the educator (and they believe this is always the case), an underlying set of assumptions (whether they be tacit or explicit) will, and should, drive the decision. They provide overview descriptions of five psychological perspectives, contrasted in terms of epistemology, ontology, unit of analysis, and whether they suggest dualist relationships. These theories (behaviorism, cognitivism, cognitive constructivism, sociocultural/historicisim and situativity theory) provide frameworks for describing learning and designing instruction. The goal of this chapter is to clarify these distinctions and the underlying assumptions so instructional designers, classroom teachers, and educational researchers may make pedagogical decisions more explicitly.

\section{Part II: Foundations}

This part of the Handbook, led by David Merril, focuses on strategies. The various chapters in the strategies part cover both instructional and learning strategies, although the emphasis is on implications for design and development. This part of the Handbook consists of seven chapters covering: (8) representation strategies; (9) strategies for designing embodied curriculum; (10) generative learning: principles and implications for making meaning; (11) feedback strategies for interactive learning tasks; (12) technologyenhanced support strategies for inquiry learning; (13) a distributed perspective on collaborative activity; and (14) prescriptive principles for instructional design.

\section{Chapter 8: Representation Strategies}

This chapter is written by Linda L. Lohr and James E. Gall of University of Northern Colorado, USA. The authors point out that throughout the history of education as a social science, empirical research has been conducted on various representation modes of knowledge and their impact on learners. Although a number of non-objectivist (based on social phenomenology rather than physical reality) philosophies have been put forth in education, research in knowledge representations continues to be dominated by a fundamental paradigm of knowledge transfer. This chapter uses a three-tier toolbox metaphor for media-based instructional design. The top tier addresses learning theories, the middle tier addresses multimedia models, and the bottom tier addresses specific text, visuals, audio, and animation/video design guidelines. 


\section{Chapter 9: Strategies for Designing Embodied Curriculum}

This chapter is written by Sasha A. Barab and Tyler Dodge of Indiana University, USA. It provides a conceptual framework related to designing for situational embodiment; discusses three types of curricular designs, ranging from designed and emergent simulation models to participation models; and overviews various strategies for achieving each design, including examples from the literature. Specifically, the authors discuss designed simulation models (e.g. anchored instruction, problem-based learning, and cognitive apprenticeship); emergent simulation models, (e.g. case-based reasoning, project-based learning, and classroom learning communities); and participation models (e.g., participatory simulations, academic play spaces, and communities of practice). Looking across the different examples, they also discern tensions that emerge in working toward curricular embodiment - namely, tensions concerning the quality of the context (noisy vs. tailored) and the quality of the formalisms (explicit vs. implicit) guidelines.

\section{Chapter 10: Generative Learning: Principles and Implications for Making Meaning}

This chapter is written by Hyeon Woo Lee, Kyu Yon Him, and Barbara L. Grabowski of Pennsylvania State University, USA. Its primary goal is to reconceptualize the processes for making meaning by synthesizing theoretical foundations of generative learning and exploring generative learning effects by different types of learning outcomes. It is claimed that the essence of this model of generative learning is knowledge generation. Only through learners' generation of relationships and meaning themselves can knowledge be generated that is sustainablethis is the essential process of meaning making by the learner. Likewise, only those activities that involve the actual creation of relationships and meaning are classified as examples of generative learning strategies. A variety of studies reporting on results of generative strategies are claimed by the authors to have shown that, in most cases, active learner involvement produced increased gains in recall, comprehension, and higher order thinking or improvement in self-regulated learning skill. Misconception, providing feedback, and developmental appropriateness are issues that have emerged as unresolved. As such, there is much research left to do to establish specific guidelines that help the designer create a learning environment that stimulates attention and intention, promotes active mental processing at all stages and levels of learning, and provides the learner with appropriate help in the generation process guidelines.

\section{Chapter 11: Feedback Strategies for Interactive Learning Tasks}

This chapter is written by Susanne Narciss of Technische Universitaet Dresden, Germany. The purpose of this chapter is to present theoretically and empirically based guidelines for the design and evaluation of feedback strategies. To this end, the chapter describes an interactive, two-feedback-loop model that explains core factors and effects of feedback in interactive instruction (Narciss, 2006). Based on these theoretical considerations, a multidimensional view of designing and evaluating multiples feedback strategies under multiple individual and situational conditions is presented. This multidimensional view integrates recommendations of prior research on elaborated feedback, task analyses, error analyses and tutoring techniques guidelines. 


\section{Chapter 12: Technology-Enhanced Support Strategies for Inquiry Learning}

This chapter is written by Yael Kali (Technion-Israel Institute of Technology, Haifa, Israel) and Marcia C. Linn (University of California, USA). The purpose of this chapter is to highlight eight pragmatic design principles from the Design Principles Database that are most likely to support learning, and to provide evidence that shows how learning is supported by features in technologies that apply these principles. The authors discuss the advantages and limitations of design principles to guide a design process and suggest that, for design principles to be more effective for guiding new innovations, they should be complemented with a design patterns approach.

\section{Chapter 13: A Distributed Perspective on Collaborative Activity}

This chapter is written by Thomas Satwicz (University of Georgia, Athens) and Reed Stevens (University of Washington Georgia, USA). Its purpose is to take a look at how studies of collaborative learning have developed over time in relation to a shift away from exclusively individualistic conceptions of human activity in educational research and design. The authors use prescriptions for and descriptions of collaborative learning as two general categories for understanding research and design. By prescriptions, they mean ideas, principles, and representations of designs for collaboration. By descriptions, they mean empirical accounts of collaboration. In their view, a broad survey of writing on collaborative activity displays an imbalance; they are relatively light on descriptions and heavy on prescriptions. Toward tipping this imbalance back, they argue that a productive perspective for casting descriptions of collaborative learning is a distributed one. A distributed perspective is one that considers human activity in relation to both other people and things. They conclude by using the distributed perspective to challenge researchers to consider technological artifacts as inherently collaborative and to move their work forward under this assumption.

\section{Chapter 14: Prescriptive Principles for Instructional Design}

This chapter is written by Thomas M. David Merrill (Florida State University), Matthew Barclay (Utah State University), Andrew van Schaak (Vanderbilt University), and Reed Stevens (University of Washington Georgia, USA). Its purpose is to review some of the prescriptive principles that, based on research or experience, have been identified for facilitating effective, efficient, and engaging instruction. For this purpose, instruction is defined as a deliberate attempt to design a product or environment that facilitates the acquisition of specified learning goals. This chapter first reviews the first principles of instruction identified by Merrill (2002a). In the second section, recent specifications of instructional design principles are compared to these first principles. The final section reviews approaches for designing instruction centered in whole tasks.

\section{Part III: Technologies}

This part of the Handbook, led Mike Spector, focuses on technologies. It consists of 17 chapters on both digital and non-electronic technologies, intelligent and non-intelligent technologies, and planning and evaluation technologies, as well as technologies for implementation. 


\section{Chapter 15: Programmed Technologies}

This chapter is written by Barbara B. Lockee, Miriam B. Larson, John K. Burton, and D. Michael Moore of Virginia Polytechnic Institute and State University, USA. The purpose of this chapter is to addresses the historical evolution of programmed technologies, their underlying psychological principles and characteristics, and the extensive research base that formed the early foundations of the IDT field. The most prominent models of programmed technologies are reviewed, including programmed instruction (PI), Personalized System of Instruction (PSI), and Precision Teaching (PT). Programmed Technologies represent some of the most empirically investigated forms of instruction, with decades of studies that examined their effectiveness. The modified application of programmed technologies in current models of teaching and learning reflects the long-standing impact of these design approaches on instructional systems development.

\section{Chapter 16: Educational Hypertext}

This chapter is written by Barbara Dale S. Niederhauser of lowa State University, USA. It, grounded on cognitive flexibility theory and the construction-integration model, focuses on current empirical research that furthers the authors' understanding of learning from hypertext. They point out that clearly, one's goals for reading a given hypertext play an important role in determining what is learned from it. They believe that the degree to which these goals are self or externally imposed, the specificity of goals, and the interactions among goals, system structure, and individual characteristics of learners all influence what is learned when reading hypertext. Further, strategies readers use to navigate through hypertext content, and the inclusion of navigational scaffolds, also appear to influence learning. Finally, individual characteristics, such as prior knowledge and cognitive style, also appear to affect learning from hypertext, while metacognitive aspects such as active knowledge construction and self-regulated learning, coupled with coherence-promoting hypertext design elements, hold great promise for future research.

\section{Chapter 17: Computer-Mediated Technologies}

This chapter is written by Arthur C. Graesser, Patrick Chipman, and Brandon G. King of University of Memphis, USA. It reviews research on the application of computer-mediated technologies to learning. This includes traditional computer-based training, multimedia, hypertext and hypermedia, interactive simulation, intelligent tutoring systems, inquiry-based information retrieval animated pedagogical agents, virtual environments with agents, serious games, and collaborative learning environments. Most of these systems encourage active learning, knowledge construction, inquiry and exploration on the part of the student, as opposed to being exposed to information delivery systems. The authors advocate a research roadmap for the future that systematically investigates a broad landscape of learning technologies $(T)$, pedagogical mechanisms $(M)$, learning goals $(G)$, and learner characteristics (L). They claim that a well-understood TMGL landscape will provide a principled foundation for assigning the right learning environment to the right learner at the right time. Since the costs of developing advanced learning environments are often high, they encourage designers to follow standards for reusing learning objects, lessons, and systems 
developed by the research community. They believe that one major technical challenge will be to develop authoring tools to make it easy for designers, instructors, and students to develop new content that incorporates these advanced learning technologies.

\section{Chapter 18: Computer-Mediated Communications Technologies}

This chapter is written by Jay Pfaffman of University of Tennessee, USA. It reports recent research on using text-based computer-mediated communication (CMC) in educational settings. As it is known, CMC takes many forms, and the tools available are many. An outline of CMC features and their affordances is presented as a means to draw the attention of those designing, evaluating, or describing communication environments to the features - technical and social-that are the essence of the activity and away from the particular applications that provide them. The goals of research using CMC are widely varied. Some research focuses on how a particular activity is connected to a measure of learning. Other research focuses on the nature of $\mathrm{CMC}$ and how various forms differ from one another. With the tacit assumptions that people learn from thoughtful evaluation and respond to the ideas of others, some research looks at ways to increase participation or guide learners to communicate in particular ways. Because CMC is not affected by time or place, it is also used as a means for teacher training and reduction of the isolation that many educators feel.

\section{Chapter 19: K-12 Library Media Centers}

This chapter is written by Delia Neuman of University of Maryland, USA. The author points out that: Since the early 20th century, public school library media centers in the United States have housed non-print educational materials. Since the middle of that century, K-12 library media specialists have designed learning experiences integrating these materials into classroom practice. For today's library media specialist, technology (both as materials and as process) is essential. Current American standards highlight instructional leadership, collaboration with teachers, and technology as the three integrating issues essential to the library media program (AASL and AECT, 1998). Much early research focused on developing and explaining the multifaceted role of the library media specialist. Until the 1990s, few studies looked at the relationship of K-12 library media programs to student learning. Since then, about two dozens of studies have investigated that link. The political focus of much of this work is undeniable; concerns about the absence of library media from key national legislation related to American schooling have led to research designed to establish links between library media programs and student achievement. Similar pressures in the United Kingdom and Australia have led to comparable efforts there. Quantitative and qualitative approaches have been used to (1) demonstrate widespread correlations between highquality library media programs and student learning, and (2) identify specific contributions of such programs. Various recent initiatives suggest an expansion of K-12 school library media research and a wider dissemination of its findings.

\section{Chapter 20: Technology-Based Knowledge Systems}

This chapter is written by lan Douglas of Florida State University, USA. The author points out that: Knowledge is collected and organized into technology-based systems in various ways to 
support learning and performance. Four main types of systems are identified under the general term of knowledge systems: (1) expert or knowledge-based; (2) knowledge management; (3) knowledge communities; and (4) hybrid systems that combine elements of the other types. Expert systems are computer programs that use knowledge derived from human experts to provide guidance to novices. A number of these systems have been adapted to assist in learning. Expert systems use captured knowledge to help a computer program provide assistance to a user. In knowledge management systems, the knowledge is captured and organized for direct access by the user. The third type of system is aimed at facilitating direct human-to-human communication of knowledge and includes research that comes under the categories of communities of practice or knowledge communities. This area also includes informal knowledge sharing networks that emerge through such technologies as instant messaging. This chapter highlights research issues that cut across the three approaches, including how knowledge is derived from human sources; how knowledge is encoded in a machine readable form; how collections of digital knowledge are organized using taxonomies, metadata, and ontology; and knowledge quality assurance.

\section{Chapter 21: Flexible Learning and the Architecture of Learning Places}

This chapter is written by Peter Goodyear of CoCo Research Centre, Australia. The author points out that as people take more control over their learning activity, there is a multiplication of the possible influences of time and space on their learning. If learning can take place anywhere, then we need to know more about the pedagogical affordances of the various wheres in which it is situated. This becomes a priority for the effective learner-needing to know how to select and configure appropriate learn-places-as well as for researchers trying to understand the sometimes subtle connections between place and learning. The chapter offers a summary description of flexible learning and then moves on to consider the relations between learning and place. The account is structured, in part, by a distinction between weaker and stronger interpretations of what is meant by situated learning. The function of the weaker interpretation is to highlight the importance of the learning context, such that we can focus on the affordances of the learnplace and consider the ergonomics of supportive learning environments. The stronger interpretation of situated learning causes us to take seriously the idea that being a learner is first and foremost engagement in a cultural practice, that people have to learn to engage in such cultural practices, and that place has a distinctive role in cultural practice. Paradoxically, ideas about flexible learning and mobile learning help us put learning in its place.

\section{Chapter 22: Enabling Time, Pace, and Place Independence}

This chapter is written by Som Naidu of University of Melbourne, Australia. It examines technologies that enable time and place independence. Its particular focus is on the affor-dances of these technologies: their ability to support self-paced (earning, offline or online, and group-based learning, asynchronously or synchronously. Self-paced earning offline is a mode of learning that enables indi-viduals to study with the help of portable technologies in their own time, at their own pace, and in their own place. Technologies that support this mode of learning include printed books and a whole range of portable ion-print media. Self-paced learning online is a mode of learning that enables individuals to study online and in their own time, at their own pace, and possibly from their own place. The most prominent technologies that support this model of learning include the Internet and various other computer-mediated communications tech- 
nologies. Group-based learning asynchronously is a mode of learning that enables individuals to learn in groups with online technologies but in their own time, at their own pace, and from their own place. Technologies that support this mode of learning include online learning management systems, mailing lists, bulletin boards, Web logs, and wikis. Group-based learning synchronously is a mode of learning that enables individuals to learn in groups with online technologies at the same time and the same pace as that of the group, but from different places. Commonly known technologies that allow this kind of flexibility are audio and video conferencing, broadcast radio and television, and newer technologies such as Internet telephony (VoIP), inter-relay chat, and online games and simulations.

\section{Chapter 23: Blended Learning Environments}

This chapter is written by Charles R. Graham (Brigham Young University) and Charles Dziuban (University of Central Florida), USA. The authors point out that: In recent decades, rapid technological innovation has facilitated a convergence between traditional face-to-face and distributed (or technology-mediated) learning environments. These blended learning environments try to take advantage of the strengths of both archetypal learning environments (Graham, 2006). The emergence of blended learning is highlighted in higher education and in industry training literature. The Chronicle of Higher Education reports that the President of Pennsylvania State University regards the convergence between online and residential instruction as the "single greatest unrecognized trend in higher education today" (Young, 2002, p. A33). Similarly, the American Society for Training and Development identifies blended learning as one of the top ten emergent trends in the knowledge delivery industry (Finn, 2002). Yet, surprisingly, we understand little about the nature of blended learning systems. This chapter identifies core issues and research about blended learning using the Sloan Consortium's five pillars (learning effectiveness, student satisfaction, faculty satisfaction, cost effectiveness, and access) as an organizing framework (Lorenzo and Moore, 2002). The authors also discuss future directions in blended learning research.

\section{Chapter 24: Adaptive Technologies}

This chapter is written by Valerie J. Shute (Florida State University) and Diego Zapata-Rivera (Educational Testing Service, Princeton, New Jersey, USA). The chapter describes research and development efforts related to adaptive technologies, which can be combined with other technologies and processes to form an adaptive system. The goal of an adaptive system, in the context of this chapter, is to create an instructionally sound and flexible environment that supports teaming for students with a range of abilities, disabilities, interests, backgrounds, and other characteristics. After defining key terms and establishing a rationale for adaptation, the authors present a general framework to organize adaptive technologies. They then describe experts' thoughts on what to adapt and how to adapt. The authors conclude with a summary of key challenges and potential futures of adaptive technologies.

\section{Chapter 25: Generational Differences}

This chapter is written by Thomas C. Reeves and Eunjung Oh of University of Georgia, USA. The authors point out that generational differences are the subject of much popular 
speculation but relatively little substantive research. Among the speculations are suggestions that instructional designers should take generational differences into account when developing instruction and that games and simulations will be more effective learning environments with today's younger generation than they have been with earlier ones. This review examines the evidence in both the research and popular literature that supports (or fails to support) these speculations. Most of the popular literature on the subject of generational differences appears to rest on limited data, almost always conducted by survey methods characterized by a lack of reliability and validity data. The most recent research based on rigorous analysis of previous psychological studies does yield some evidence of substantive generational differences, especially between those generations horn before and after 1970. Recommendations for further research in this area include examining generational differences across the whole spectrum of socioeconomic status and in international contexts, as well as implementing innovative design-based research approaches to accommodating generation differences in the process of instructional design.

\section{Chapter 26: Technologies Linking Learning, Cognition, and Instruction}

This chapter is written by Sabine Graf (Vienna University of Technology, Vienna, Austria) and Eunjung Oh Kinshuk (Athabasca University, Athabasca, Canada). The authors begin with point that people prefer to learn in many different ways. Furthermore, individuals have different cognitive abilities that influence the way effective learning takes place. Incorporating individual differences such as learning styles and cognitive abilities into education makes learning easier and increases the learner's performance. In contrast, learners whose needs are not supported by the learning environment experience problems in the learning process. Then they introduce some cognitive traits that are important for learning and also discuss how to incorporate different abilities in educational systems. In regard to learning styles, some major approaches as well as possible strategies for involving learning styles in online courses are presented. After that, recent research dealing with identifying learning styles and cognitive traits based on the behavior of students during a course is presented. This information is necessary to provide adaptive courses. Finally, the relationship between cognitive traits and learning styles is discussed. This relationship leads to additional information and therefore to a more reliable student model.

\section{Chapter 27: Synthetic Learning Environments}

This chapter is written by Janis A. Cannon-Bowers and Clint A. Bowers of University of Central Florida, USA. A variety of technology-based interventions have been proposed to accelerate learning. Although these technologies have enjoyed some success, we need a better understanding of the manner in which specific technologies affect the pedagogical factors associated with enhanced learning. In this chapter, the authors attempt to articulate a path forward for the development of synthetic learning environments by identifying variables that are important to their effectiveness. Further, they articulate the conditions under which such technologies are most likely to be successful.

\section{Chapter 28: Modeling Technologies}

This chapter is written by Roy B. Clariana (Pennsylvania State Great Valley, USA) and Johannes Strobel (Concordia University, Montreal, Canada). The authors start with explaining that 
modeling technologies are a powerful tool for affecting learning. Although dynamic modeling is not an easy task, modeling technologies are maturing. As tools become easier to use, more people will build models, and this is likely to drive learning theory and practice in new directions. The chapter centers on one aspect of modeling: dynamic modeling with technology, where students build dynamic models that "run." This chapter particularly does not address other forms of modeling technologies such as concept mapping (as a form of modeling domain knowledge), expert systems (modeling of problems), and case databases (modeling experiences). The chapter begins with the conceptual framework for modeling with technology, describes extant dynamic modeling tools, reviews investigations of the factors associated with modeling technologies in the classroom, and points to future design and research.

\section{Chapter 29: The Learning Objects Literature}

This chapter is written by David A. Wiley of Utah State University, USA. This chapter can be summarized as follows: The learning objects literature is a collection of journal articles, book chapters, white papers, and blog entries that as a whole recognize few seminal works, share few common definitions of terms, and rarely reference or build upon one another. Learning objects research generally falls into one of two categories. The traditional approach to using learning objects focuses on enabling the just-in-time automated assembly of carefully structured learning objects to create personalized educational experiences. The permissive approach to using learning objects focuses on making the reuse and localization of all resources, regardless of their structure, as effective and efficient as possible. The field is subject to a large number of criticisms. Nascent work in open educational resources points to the likely future of the field.

\section{Chapter 30: Open Source and Open Standards}

This chapter is written by Rob Koper of Open University of the Netherlands. The objective of this chapter is to create an understanding of the importance of open source software and open standards (OSS/OS) for e-learning research. Open source is a fundamental new way to develop software, and open standards are needed to make software components work together. It is argued that OSS and OS can improve the convergence of knowledge in the e-learning field, improve the general quality and interoperability of e-learning applications, and improve collaboration between researchers and users. AH of these are beneficial and necessary requirements for e-learning research. After a general introduction into basic OSS and OS concepts, the following questions are answered: (1) How does OSS/OS facilitate the technological activities of the researchers in terms of methodology, collaboration, and dissemination of results? (2) How does OSS/OS facilitate the development of technological knowledge in the field? (3) How does OSS/OS facilitate the development of technological artifacts in the field? The development and use of the open standard IMS Learning Design (a formal design language for online courses) and the open source applications that are developed to run and present IMS Learning Design courses are used as an example to demonstrate the use of OSS/OS in e-learning research. In the concluding section, the authors provide some practical information for researchers on how to get involved in OSS and OS and how to use them in e-learning research field. 


\section{Part IV: Models}

This part of the Handbook is led by Jeroen van Merrienboer and focuses on models. Issues concerned with various types of and approaches to learning are discussed. These models clearly inform design and development and can be linked to various instructional strategies covered in Part II. The Models part includes general models directed toward learning in schools as well as outside schools and models that focus on learning in specific domains such as medicine, science, and reading.

\section{Chapter 31: Human Cognitive Architecture}

This chapter is written by John Swelter of University of New South Wales, Sydney, Australia. This chapter outlines the evolutionary bases for human cognitive architecture, examines those aspects of human cognition that are directly relevant to instruction, and discusses the various instructional principles generated by cognitive load theory with specific reference to their applicability to instructional technology.

\section{Chapter 32: Outcome-Referenced, Conditions-Based Theories and Models}

This chapter is written by Tillman J. Ragan and Patricia L. Smith (University of Oklahoma) and L. K. Curda (University of West Florida), USA. The underlying discussion of this chapter can be summarized as follows: One of the most influential and pervasive theories underlying instructional design proposes that (1) there are identifiably different types of learning outcomes, and (2) the acquisition of these outcomes requires different internal and external conditions of learning. These propositions underlie an outcome-referenced, conditions-based paradigm of instructional design (ID). The outcome-referenced, conditions-based perspective is commonplace, if not universal, in current instructional psychology and instructional design thinking, even when the author's orientation and values are not based on the cognitive science that underlies this perspective. Whether or not individuals formally subscribe lo or have an interest in these theories and models, it is part of the everyday work of instructional designers and scholars of instruction and learning environments. This chapter (1) presents the assumptions of the outcome-referenced, conditions-based perspective, (2) describes prevalent theories and models within this tradition, and (3) provides future directions for research and development.

\section{Chapter 33: Cooperation and the Use of Technology}

This chapter is written by David W. Johnson and Roger T. Johnson of the University of Minnesota, Minneapolis, Minnesota, USA. The chapter can be summarized as follows: Technology may be more productively utilized when it is combined with cooperative learning. There are four types of cooperative learning: formal cooperative learning, informal cooperative learning, cooperative base groups, and academic controversy. Cooperative learning's worldwide use is based on a well-formulated theory (i.e., social interdependence theory) that has been validated by numerous research studies and operationalized into practical procedures that can be used at any level of education. Technology-supported cooperative learning tends to increase achievement (both academic achievement and learning how to use technology), positive attitudes (toward technology and cooperation), 
healthy development (cognitive development, learning control, social competencies), positive relationships with team members (including social presence), and innovation in groupware and hardware. Cooperative learning and technology-supported instruction have complementary strengths. The computer, for example, can control the flow of work, monitor accuracy, give electronic feedback, and do calculations. Cooperative learning provides a sense of belonging, the opportunity to explain and summarize what is being learned, shared mental models, social models, respect and approval for efforts to achieve, encouragement of divergent thinking, and interpersonal feedback on academic learning and the use of the technology. The use of cooperative learning with technology-assistedinstruction results in more positive attitudes toward technology (especially by females) and allows for argumentation (i.e., constructive controversy) to be part of lessons utilizing technology. Cooperative learning is an important part of enhancing the effectiveness of interacting around computers and interacting through computers (e.g., local networks, email, videogames and simulations, adventure learning, and interacting with electronic pedagogical agents).

\section{Chapter 34: The Cognitive Apprenticeship Model in Educational Practice}

This chapter is written by Vanessa P. Dennett and Kerry J. Burner of Florida State University, Tallahassee, Florida, USA. Cognitive apprenticeship is a process by which learners learn from a more experienced person by way of cognitive and metacognitive skills and processes. This chapter explores the elements of cognitive apprenticeship, first offering definitions and a historical context, then moving into a review of research. The research review is organized with a three-part focus: on studies that investigate a holistic approaches to educational applications of the process of cognitive apprenticeship; on studies that investigate portions of the process, such as scaffolding or mentoring; and on studies that investigate cognitive apprenticeship activities within communities of practice. Discussion about the intersection of technology and cognitive apprenticeship research is imbedded within each of the three areas of focus, reflecting the steady increase of systematically designed, computermediated instruction that is based in social learning theories, especially cognitive apprenticeship theories. Empirical studies have confirmed much of what theories have suggested: (1) that the cognitive apprenticeship model is an accurate description of how learning occurs, and (2) that the instructional strategies that have been extracted from these observations of everyday life can be designed into more formal learning contexts with positive effect. The chapter concludes with a call for more systematic and integrated program of studies working toward the development of guiding principles to support instructional design, teaching, and learning based on the cognitive apprenticeship model.

\section{Chapter 35: Whole-Task Models in Education}

This chapter is written by Jeroen J. G. van Merrienboer and Liesbeth Kester of Open University of the Netherlands, Heerlen, the Netherlands. Whole-task models support the development of educational programs for students who need to learn and transfer professional competences or complex cognitive skills to an increasingly varied set of real-world contexts and settings. They are a reaction to traditional atomistic approaches in which complex contents and tasks are reduced into increasingly simpler elements until reaching a level where the distinct elements can be transferred to the learners through presentation or practice. These approaches work well if there are few interactions between the elements, but they do not 
work well if the elements are interrelated because the whole is then more than the sum of its parts. Whole-task models basically try to deal with complexity without losing sight of the relationships between elements. This chapter briefly discusses the history of whole-task models. They are rooted in motor learning and sports, andragogy and adult learning, and Gestalt psychology. The characteristics of whole-task models in the field of educational communications and technology are also discussed. Elaboration theory, goal-based scenarios, and four-component instructional design are presented as three representative examples of whole-task models. The authors present empirical evidence for the effectiveness of the whole-task approach and the three example models. We conclude with a summary of findings and directions for future research on whole-task models.

\section{Chapter 36: Model-Facilitated Learning}

This chapter is written by Ton de Jong and Wouter R. van Joolingen of University of Twente, Enschede, the Netherlands. This chapter discusses the possible roles of models in learning, focusing on computer models (simulations). In learning from models, students' learning processes center around the exploration of a model by changing values of input variables and observing resulting values of output variables. In this process, they experience rules of the simulated domain or discover aspects of these rules. Models can also play a role in the learning process when we ask students to construct models. In learning by modeling, students are required to construct an external model that can be simulated to reproduce phenomena observed in a real system. Finally, both ways of using models can be combined in what we refer to as model-based inquiry learning. Here, students encounter a computer model that they can explore by changing values of the input variables and by observing values of the output variables and then they reconstruct the model, including its internal functioning, so both models will behave similarly.

\section{Chapter 37: Adaptive Instructional Systems}

This chapter is written by Jung Lee (The Richard Stockton College of New Jersey, Pomona, New Jersey) and Ok-Choon Park (Institute of Education Sciences, Washington, D.C.), USA. This chapter summarizes five approaches to adaptive instruction, which embodies all instructional forms that accommodate the needs and abilities of different learners: (1) macro-adaptive instruction; (2) aptitude-treatment interactions (ATI-based); (3) microadaptive instruction, including intelligent tutoring systems (ITSs); (4) the adaptive/adaptable hyper-media/Web-based system (AHS); and (5) specific pedagogy-centered systems. These approaches are presented in historical order, beginning with macro-adaptive systems. For each approach, its characteristics and representative systems are discussed. Although each has its own distinctive properties, some similarities can be found among the approaches. Due to the development of information and communication technology (ICT), the structural functions of recent adaptive systems are significantly more powerful than earlier ones. New Web-based systems have functions that simultaneously provide customized learning experiences to masses of individual learners. The challenges now facing researchers and developers are to optimally integrate many different theories, principles, and strategies of learning and instruction with system functions and to prove empirically the effects and value of these systems in real-world environments. 


\section{Chapter 38: Problem-Based Learning}

This chapter is written by Woei Hung (University of Arizona South, Siena Vista, Arizona), David H. Jonassen (University of Missouri, Columbia, Missouri), Rude Liu (Beijing Normal University, Beijing, China). According to the authors, problem-based learning (PBL) is perhaps the most innovative instructional method conceived in the history of education. PBL was originally designed to respond to the criticism that traditional teaching and learning methods fail to prepare medical students for solving problems in clinical settings. Instead of requiring that students study content knowledge and then practice context-free problems, PBL embeds students' learning processes in real-life problems. After its successful implementation in various fields of medical education, PBL is now being implemented throughout higher education as well as in $\mathrm{K}-12$ education. The purpose of this chapter is to inform researchers and practitioners about research findings and issues in PBL that may be used to inform future studies. The authors review PBL research from the past 30 years. They first describe the history of development and implementation of PBL in various educational settings and define the major characteristics of PBL. They then review the research on PBL. First, they examine the effectiveness of PBL in terms of student learning outcomes, including basic domain knowledge acquisition and applications, retention of content and problem-solving skills, higher order thinking, self-directed ]earning/lifelong learning, and self-perception. Second, they look at implementation issues, such as tutoring issues, curriculum design issues, and use of technology. Finally, the authors provide recommendations for future research.

Chapter 39: Behavioral, Cognitive, and Technological Approaches to Performance Improvement

This chapter is written by Ruth Colvin Clark (Clark Training and Consulting, Cortez, Colorado) and Frank Nguyen (San Diego State University, San Diego, California), USA. Often, training fails to improve organizational outcomes. Increasingly, practitioners are assuming a performance improvement perspective that takes a holistic and systemic perspective in analyzing causes of and solutions for gaps in organizational results. The authors review the models and evidence for three perspectives on performance improvement: behavioral engineering, cognitive-motivational, and technological. The behavioral engineering models prevalent among U.S. practitioner-oriented professional societies apply a pragmatic systemic approach that evaluates performance factors at the organizational, process, and individual worker or team levels. The cognitive-motivational approaches prevalent among industrial and organizational psychologists include guidelines for goal setting, feedback, and incentives. The cognitive models are based on empirical evidence and incorporate motivational and cognitive moderators of their interventions. Recent advances in computer technology offer opportunities to deliver performance support in new ways. In our discussion of technological approaches, we focus primarily on the evolution of and evidence for electronic performance support systems (EPSSs) in the workplace.

\section{Chapter 40: Resource-Based Learning}

This chapter is written by Michael J. Hannafin and Janette R. Hill of University of Georgia, Athens, Georgia, USA. The nature of information has changed dramatically during the past 25 years. The digital age has redefined the nature of a resource and dramatically changed how 
resources are used to support learning. Media of often unknown origin and quality are now used across a wide range of learning systems to address diverse epistemological beliefs and associated learning goals. The number and types of resources have also grown exponentially. Several factors increase the viability of resources for learning, including access to resources in contexts not previously available, increased flexibility in their use, and ready availability, manipulability, and sharability. The purposes of this chapter are to present a brief historical perspective on resource-based learning; describe components of resource-based learning; introduce the influence of underlying epistemology, foundations, and assumptions in grounding resource use; critically analyze related research; and identify implications for RBL.

\section{Chapter 41: Instructional Models in Domains and Professions}

This chapter is written by Henny P. A. Boshuizen (lead author) (Open University of the Netherlands, Heerlen, the Netherlands), Caroline Phythian-Sence and Richard K. Wagner (Florida State University, Tallahassee, Florida), Koeno Gravemeijer (Utrecht University, Utrecht, the Netherlands), Geerdina Maria van der Aalsvoort (Leiden University, Leiden, the Netherlands), Fleurie Nievelstein, Tamara van Gog and Frans J. Prins (Open University of the Netherlands, Heerlen, the Netherlands), Tim Dornan (University of Manchester, Manchester, England), Albert Scherpbier (Maastricht University, Maastricht, the Netherlands) and John Spencer (University of Newcastle, Newcastle, England).

This chapter investigates grounds for the application and adaptation of general instructional models in specific domains and professions and for the generation of domain-specific instructional methods using the examples of reading, mathematics, science, law, and medicine. It does so by first investigating the specific teaching and learning difficulties of those domains by showing and analyzing domain- and profession-specific solutions to these problems. The chapter consists of a general analysis of the problems with general instructional design models that have to be solved before they can be used in specific domains, the requirements for the use of these models, and the effects of internal and external pressures for change.

\section{Part V: Design and Development}

This part of the Handbook, led by M. David Merrill, focuses on design and development. It discusses research that pertains directly to professional practice. This part of the Handbook consists of eleven chapters. Readers will find chapters on familiar topics such as competency development, task analysis, change agency, and performance assessment. The Design and Development part also covers innovative treatments of design languages, design and development teams, and user-centered design and development.

\section{Chapter 42: Competencies for the New-Age Instructional Designer}

This chapter is written by Roderick C. Sims (Capella University, Woodburn, New South Wales, Australia) and Tiffany A. Koszalka (Syracuse University, Syracuse, New York). This chapter provides an analysis of current competencies (i.e., knowledge, skills, and attitudes) that are necessary to achieve effective instructional design and development outcomes with specific focus on contemporary technology-mediated educational applications. Referring to current 
competency standards and models, such as those devised by ibstpi ${ }^{\circledR}$, this chapter elaborates on those competencies essential for supporting the integration of hardware and software technologies (mobile devices, personal blogs, multiplayer environments) into collaborative instructional networks. In addition, the analysis identifies recent models of design that provide a framework for educational professionals to ensure that they have the knowledge, skills, and attitudes to effectively manage the challenges and utilize the affordances of educational technology in today's complex social settings. By understanding these shifts, instructional designers will appreciate the expanding and changing nature of their role.

\section{Chapter 43: Cognitive Task Analysis}

This chapter is written Richard E. Clark (University of Southern California, Los Angeles, California), David F. Feldon (University of South Carolina, Columbia, South Carolina), Jeroen J. G. van Merrienboer (Open University of the Netherlands, Heerten, the Netherlands), Kenneth A. Yates (University of Southern California, Los Angeles, California) and Sean Early (University of Southern California, Los Angeles, California). It presents an overview of the current state of cognitive task analysis (CTA) in research and practice. CTA uses a variety of interview and observation strategies to capture a description of the explicit and implicit knowledge that experts use to perform complex tasks. The captured knowledge is most often transferred to training or the development of expert systems. The first section presents descriptions of a variety of CTA techniques, their common characteristics, and the typical strategies used to elicit knowledge from experts and other sources. The second section describes research on the impact of CTA and synthesizes a number of studies and reviews pertinent to issues underlying knowledge elicitation. In the third section, we discuss the integration of CTA with training design. Finally, in the fourth section, the authors present a number of recommendations for future research and conclude with general comments.

\section{Chapter 44: Design and Validation of Technology-Based Performance Assessments}

This chapter is written by Eva L. Baker, Gregory K. W. K. Chung, and Girlie C. Delacruz of UCLA/CRESST, Los Angeles, California, USA. This chapter describes approaches to the design and technical verification of assessments of performance. The chapter begins with a brief definition of performance measurement and describes a set of validity criteria that should be in place to guide the design of performance assessments that may serve multiple purposes. Design criteria include descriptions of families of cognitive demands, approaches to ensure content representation, and templates or objects to promote economic design and renewal. The authors then illustrate with multiple examples from K-12 education and from the training community. The context of most of the chapter is the use of technology tools for design, administration, and automated scoring. This chapter concludes with future directions in performance measurement and its implications.

\section{Chapter 45: Models and Methods for Evaluation}

This chapter is written by Ron Owston of York University, Toronto, Canada. It situates the evaluation of technology-based programs in the context of the field of general educational program evaluation. It begins with an overview of the main evaluation approaches devel- 
oped for general educational programs, including Tyler's early conception of assessing attainment of program objectives, decision-making approaches, naturalistic evaluation, and Kirkpatrick's four levels for evaluating program effectiveness. Following this is an overview of commonly used technology-specific program evaluation criteria and frameworks. Strategies distilled from these two fields are then suggested for evaluating technologybased learning programs. These strategies emphasize clarifying the goal or purpose of the evaluation and determining the information needs of the intended audiences of the evaluation at the beginning of the project. This, in turn, suggests the most appropriate evaluation methodology to be used. The chapter concludes with a description of tools that can be used for analysis of evaluative data, followed by a brief discussion of the dissemination of evaluation results.

\section{Chapter 46: Change Agentry}

This chapter is written by Brian Beabout and Alison A. Carr-Chellman of Pennsylvania State University, USA. It presents theoretical foundations and empirical findings of the construct of change agentry in order to aid change agents and scholars in effecting substantive organizational or educational change. Familiarity with this literature gives credibility to those of us in the educational communications and technology field seeking to effect significant change through collaborative efforts. The authors begin by defining change agentry and focusing on the theoretical foundations of change theories, agency theories, and diffusion theories. After this consideration of theoretical constructs, they turn to an examination of the empirical findings in research studies associated with K-12 school contexts, government organizations, corporations, and the health care industry. Their findings indicate three core ideas central to change agentry: (1) connecting an organization to its environment is important; (2) flexibly adaptive change may be a desired goal, and (3) local leaders as well as external supports are needed to support any successful change effort.

\section{Chapter 47: Design Languages}

This chapter is written by Andrew S. Gibbons (Brigham Young University, Provo, Utah), Luca Botturi (NewMinE Lab, University of Lugano, Lugano, Switzerland), Eddy Boot (TNO Human Factors, Soesterberg, the Netherlands) and Jon Nelson (Utah State University, Logan, Utah). The chapter can be summarized as follows: Design languages and notation systems hold great practical and theoretical significance for instructional design. Instructional designers use multiple design languages in the creation of designs. Notation systems make design languages visible and document those solutions. Design languages provide the building blocks of an evolving design. Design languages are used by individual designers; shared design languages and notation systems are necessary for multi-participant design teams to function, even at a basic level. Design languages for instructional design allow us to view instructional design, instructional theory, and daily practice in a new way that enhances our understanding of all of them.

\section{Chapter 48: The Social Consequences of Design and Development Teams}

This chapter is written by Laura Blasi and Stephen M. Fiore (University of Central Florida, Orlando, Florida), John Hedberg (Macquarie University, North Ryde, New South Wales, 
Australia) and Richard F. Schmid (Concordia University, Montreal, Quebec, Canada). Providing a brief history of the work of design and development (D\&D) teams grounded in the relevant literature, this chapter offers several prominent examples from the past 65 years. These examples allow the comparison of the context for design and development focused on industry, government, and education. The authors highlight models for developing teams that are especially useful to those who are new to the field. They conclude with challenges faced by design and development teams specifically in regard to educational communications and technology. Design and development teams should: (1) organize in ways informed by the research; (2) access and apply research on teaching and learning; (3) conduct research for ongoing evaluation of technology in education; and (4) contribute to the research in the field from their own innovations, mindful of the social consequences of design and development

\section{Chapter 49: User-Centered Design and Development}

This chapter is written by Eun-Ok Baek (California State University, San Bernardino, California), Kursat Cagiltay (Middle East Technical University, Ankara, Turkey), Elizabeth Baling and Theodore Frick (Indiana University, Bloominglon, Indiana). The chapter surveys methods, techniques, practices, and challenging issues in user-centered design and development (UCDD). The traditional instructional systems design (ISD) approach has been criticized for its bureaucratic and linear nature and its slow process. Two alternatives to that approach are discussed here. They are rapid prototyping and participatory design. These have been put forth as alternative models that address the many limitations of the conventional ISD model.

\section{Chapter 50: Tools for Design and Development of Online Instruction}

This chapter is written by Bryan L. Chapman of Brandon Hall Research/Chapman Alliance, Sunnyvale, California, USA. The aim of this chapter is to explore the tools that instructional designers and novice developers use most often to create online learning from both a design and development perspective, the types of instructional design support that can be found in different types of development tools, and how these tools may (or may not) impact the ability to meet instructional needs. A classification system is used to analyze tools as (1) standard authoring tools, (2) front-end design and automated instructional design (AID) tools, (3) simulation and gaming tools, or (4) team development or publishing tools such as learning content management systems (LCMSs) and groupware authoring. Although instructional design guidance, in some form or another, is now embedded inside several classifications of development tools, considerable innovation and research are still required to create holistic systems that negate or minimize the need for instructional design expertise, allowing nontrained designers to create online learning courseware without assistance.

\section{Chapter 51: Artifacts as Tools in the Design Process}

This chapter is written by Elizabeth Boling and Kennon M. Smith of Indiana University, Bloomington, Indiana, USA. The content of the chapter can be summarized as follows: Both process and product artifacts are collected and disseminated in many fields of design as a source of design knowledge in the form of precedent, which includes both the artifacts 
themselves and the memories, or schema, retained as a result of interaction with or examination of the artifacts. The emergence of serious study into the practice of design in our field will extend beyond the study of process models and may be productively informed by understanding how artifacts are used as tools by designers.

\section{Chapter 52: Systems Design for Change in Education and Training}

This chapter is written by Sunnie Lee Watson and Charles M. Reigeluth (Indiana University, Bloomington, Indiana) and William R. Watson (Purdue University, West Lafayette, Indiana), USA. The purpose of this chapter is to introduce current research and theory on systems design for change, or systemic change, in the fields of education and training. Systems design is the process for determining what characteristics a new system should have, resulting in a model of the new system and a plan for creating it. Systemic change is the process of changing a system from one paradigm to another by applying systems thinking and systems theory. Repeated calls for massive reform of current educational and training practices have consistently been published over the last several decades. This has resulted in an increasing recognition of the need for systemic change in education as numerous structured, piecemeal approaches to education reform have been implemented and failed to significantly improve the state of education. This chapter first presents a description of design theory and systems theory as the foundations for systems design. Design theory is the concepts and principles that help to develop strategies and methods for designing. The term system has been defined in various ways by different researchers, but the core concept is one of relationships among components comprising the whole.

\section{Part VI: Methodological Issues}

This part, led by Jeroen van Merrienboer, follows the empirical cycle through theory development, experimental design, and data collection and analysis. Design sections adhere to the main parts of the Handbook and treat, in order, research on strategies, technologies, models, and design and development. For data collection, special requirements for (virtual) laboratories are discussed. Analysis methods include the analysis of learning processes, interactions, and complex performances. The Methodological Issues part ends with a discussion by the editorial team of a research agenda that should help our field to build a strong scientific foundation for the future.

\section{Chapter 53: Theory Development}

This chapter is written by Jan Elen and Geraldine Clarebout of Katholieke Universiteit Leuven, Leuveii, Belgium. The field of educational technology is characterized by an abundance of sets of theoretical statements. These sets can be described from at least four perspectives. A first perspective pertains to the object or orientation of the (sets of) theoretical statements. Sets may address educational principles, features of interventions or tools, development procedures, or the nature of the field itself. The origin (theoretical or practical context) of these sets of statements is a second perspective from which they can be described. Theoretical statements can be clearly anchored in specific practical experiences, can be the result of a deductive effort to apply fundamental theoretical insights or theoretical perspectives, or can reflect a thoughtful interaction between a practical setting and a 
theoretical perspective. A third perspective relates to the level of theoretical sophistication of these (sets of) statements. Sets of theoretical statements can be collections of isolated theoretical expressions, descriptive or prescriptive models with respect to educational technological issues, of integrated, internally coherent sets of theoretical principles. The degree of justification of these (sets of) statements represents a fourth perspective. Some statements are purely explorative, whereas for others empirical evidence is readily available. Taking these differences into account, this chapter aims at discussing theory development. First, features of descriptive and prescriptive theories are elaborated by analyzing their commonalities and differences. Second, the development of theories itself is addressed by focusing on deductive, inductive, and mixed approaches. Third, theoretical levels of sophistication and justification are dealt with. In all this, the elaboration of instructional design models is focused upon.

\section{Chapter 54: Research Designs}

This chapter is written by Steven M. Ross (lead author of the chapter) (University of Memphis, Memphis, Tennessee), Gary R, Morrison (Old Dominion University, Norfolk, Virginia), Robert D. Hannafin and Michael Young (University of Connecticut, Storrs, Connecticut) Jan van den Akker and Wilmad Kuiper (University of Twente, Enschede, the Netherlands) Rita C. Rickey (Wayne State University, Detroit, Michigan) and James D. Klein (Arizona State University, Tempe, Arizona). This chapter examines the types of designs and methodological approaches used by educational technology and instructional design researchers to investigate: (1) instructional strategies; (2) educational technologies; (3) instructional design models; and (4) design and development of instruction. These four approaches correspond to the four main parts of the Handbook. In the opening section, Ross and Morrison discuss how experimental methods have been predominantly used in determining the effectiveness of instructional strategies used to teach specific content, affect the design of a course, or improve message design. In the second chapter section, Hannafin and Young examine how research on instructional technologies has been influenced by the manner in which technology has been conceptualized as a treatment or intervention. When it is regarded as simply a medium for learning (e.g., computer-assisted instruction), usage of highly controlled experimental designs is most common; when conceived more broadly as a technology-enhanced learning environment (TELE), use of design-based research is favored. In the third section, van den Akker and Kuiper examine design and development research focusing on models for instructional design. Specific attention is directed to analyzing the trends that are most visible in model development and validation and exploring how research on models can be redirected to foster blending of theory and practice. In the final section, Richey and Klein focus on methods and issues related to conducting research on the design and development of instruction. Studies in this area, although highly diverse, most frequently rely on qualitative techniques, including case studies, interviews, document reviews, and observations. Design and development research: Research that seeks to create knowledge grounded in data systematically derived from practice and based upon a systematic analysis of specific cases. Experiment: A design that involves the comparison of one treatment to another, using two or more different groups.

\section{Chapter 55: Data Collection and Analysis}

This chapter is written by Tamara van Gog and Fred Paas (lead authors of the chapter)(Open University of the Netherlands, Heerlen, the Netherlands), Wilhelmina Savenye (Arizona State 
University-Tempe, Tempe, Arizona), Rhonda Robinson (Northern Illinois University, DeKalb, Illinois), Mary Niemczyk Arizona State University-Polytechnic, Mesa, Arizona), Robert Atkinson (Arizona State University-Tempe, Tempe, Arizona), Tristan E. Johnson (Florida State University, Tallahassee, Florida), Debra L. O'Connor (Intelligent Decision Systems, Inc., Williamsburg, Virginia), Rerny $M$, J. P. Rikers (Erasmus University Rotterdam, Rotterdam, the Netherlands), Paul Ayres (University of New South Wales, Sydney, Australia), Aaron R. Duley (National Aeronautics and Space Administration, Ames Research Center, Moffett Field, California), Paul Ward (Florida State University, Tallahassee, Florida) and Peter A, Hancock (University of Central Florida, Orlando, Florida).

The focus of this chapter is on methods of data collection and analysis for the assessment of learning processes and complex performance, the last part of the empirical cycle after theory development and experimental design. In the introduction (van Gog and Paas), the general background and the relation between the chapter sections are briefly described. The section by Savenye, Robinson, Niemczyk, and Atkinson focuses on methods of data collection and analysis for assessment of individual learning processes, whereas the section by Johnson and O'Connor is concerned with methods for assessment of group learning processes. The chapter section by van Gog, Rikers, and Ayres discusses the assessment of complex performance, and the final chapter section by Duley, Ward, Szalma, and Hancock is concerned with setting up laboratories to measure learning and complex performance.

\section{Chapter 55: Foundations for the Future}

This chapter is written by ChanMin Kim and JungMi Lee (Florida State University, Tallahassee, Florida), M. David Merrill (Florida State University, Tallahassee, Florida), USA. J. Michael Spector (Florida State University, Tallahassee, Florida) and Jeroen J. G. van Merrienboer (Open University of the Netherlands, Heerlen, the Netherlands). The authors address five questions as a way of technology speculating about the future of scientific inquiry pertaining to educational communications and technology: (1) What have been the most significant developments in educational communications and in the last five years? (2) What are likely to be the most significant developments in the next five years? (3) What significant research findings have occurred in the last five years? (4) What are likely to be the most significant research issues in the next five years? (5) What are the most critical foundational aspects and factors for future research and development in educational communications and technology? In addition to addressing these questions, we also comment on the proper study of instructional design and how best to prepare educational technology practitioners and researchers.

\section{Conclusion}

As Joost Lowyck indicates in the foreword of the book, the information made available by acknowledged scholars in the Handbook "depicts many contributions to the foundation, strategies, technologies, models, design and development, and methodology of educational communications and technology. One of the expected outcomes of this immense knowledge base is the creation of a new generation of research and development, in which conceptual alignment, empirical richness, and synergy are spearheads of educational innovation" (p.xv). 
Overall, the Handbook is a cornerstone in the field of educational communications and technology. Starting with the first edition, it has been a very useful guide particularly for academicians and doctoral students all around the world. Compared to previous editions, this third edition consists of contributions from more authors from different countries. This international perspective alone represents a more comprehensive view of issues and approaches in educational technology. Considering its distinct nature and unique role, the Handbook of Research on Educational Communications and Technology should be available in the library of all educational technology and instructional design professionals.

Correspondence: Rauf Yildiz, Professor, Faculty of Education, Canakkale Onsekiz Mart University, Anafartalar Campus, Canakkale, Turkey. 